\title{
LUDWIG FEUERBACH
}

Gesammelte Werke

6 


\section{LUDWIG FEUERBACH GESAMMELTE WERKE}

HERAUSGEGEBEN VON

WERNER SCHUFFENHAUER

6

AKADEMIE-VERLAG - BERLIN 1984 


\section{LUDWIG FEUERBACH}

\section{Vorlesungen \\ über das Wesen der Religion}

Nebst Zusätzen und Anmerkungen

3., gegenüber der 2., durchgesehenen, unveränderte Auflage

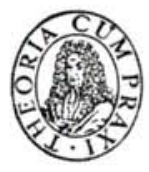

A KADEMIE-VERLAG - BERLIN

1984 


\section{Bearbeiter dieses' Bandes WOLFGANG HARICH}

Redaktion dieser Auflage

Werner Schuffenhauer

Erschienen im Akademie-Verlag, DDR-ro86 Berlin,

Leipziger Str. 3-4

(c) Akademie-Verlag Berlin 1984 (1967)

Lizenznummer : $202 \cdot 100 / 17 / 84$

Printed in the German Democratic Republic

Offsetdruck und buchbinderische Weiterverarbeitung:

VEB Druckerei „Thomas Müntzer", 5820 Bad Langensalza

LSV or 16

Bestellnummer: $7500854 \quad(4042 / 6)$

DDR 25,50 M 